\title{
High Levels of Cre Expression in Neuronal Progenitors Cause Defects in Brain Development Leading to Microencephaly and Hydrocephaly
}

\author{
Paolo E. Forni, ${ }^{1,4,5}$ Claudio Scuoppo, ${ }^{1,4}$ Itaru Imayoshi, ${ }^{6}$ Riccardo Taulli, ${ }^{1,4}$ Walter Dastrù, ${ }^{2,3}$ Valentina Sala, ${ }^{1,4}$ \\ Ulrich A. K. Betz, ${ }^{7}$ Patrizia Muzzi, ${ }^{1}$ Daniela Martinuzzi, ${ }^{1}$ Alessandro E. Vercelli, ${ }^{1}$ Ryoichiro Kageyama, ${ }^{6}$ and \\ Carola Ponzetto ${ }^{1,4,5}$ \\ ${ }^{1}$ Department of Anatomy, Pharmacology, and Forensic Medicine, ${ }^{2}$ Department of Inorganic, Physical, and Materials Chemistry, ${ }^{3}$ Center of Molecular \\ Imaging, ${ }^{4}$ Center for Experimental Research and Medical Studies, ${ }^{5}$ Rita Levi-Montalcini Center for Brain Repair, University of Turin, 10126 Turin, Italy, \\ ${ }^{6}$ Institute for Virus Research, Kyoto University, Sakyo-ku, Kyoto 606-8507, Japan, and 7Merck KGaA, Global Preclinical Research and Development, D- \\ 64293 Darmstadt, Germany
}

Hydrocephalus is a common and variegated pathology often emerging in newborn children after genotoxic insults during pregnancy (Hicks and D'Amato, 1980). Cre recombinase is known to have possible toxic effects that can compromise normal cell cycle and survival. Here we show, by using three independent nestin Cre transgenic lines, that high levels of Cre recombinase expression into the nucleus of neuronal progenitors can compromise normal brain development. The transgenics analyzed are the nestin Cre Balancer (Ball) line, expressing the Cre recombinase with a nuclear localization signal, and two nestin $\mathrm{CreER}^{\mathrm{T} 2}$ (Cre recombinase fused with a truncated estrogen receptor) mice lines with different levels of expression of a hybrid $\mathrm{CreER}^{\mathrm{T} 2}$ recombinase that translocates into the nucleus after tamoxifen treatment. All homozygous Ball nestin Cre embryos displayed reduced neuronal proliferation, increased aneuploidy and cell death, as well as defects in ependymal lining and lamination of the cortex, leading to microencephaly and to a form of communicating hydrocephalus. An essentially overlapping phenotype was observed in the two nestin CreER ${ }^{\mathrm{T} 2}$ transgenic lines after tamoxifen mediated$\mathrm{CreER}^{\mathrm{T} 2}$ translocation into the nucleus. Neither tamoxifen-treated wild-type nor nestin $\mathrm{CreER}^{\mathrm{T} 2}$ oil-treated control mice displayed these defects. These results indicate that some forms of hydrocephalus may derive from a defect in neuronal precursors proliferation. Furthermore, they underscore the potential risks for developmental studies of high levels of nuclear Cre in neurogenic cells.

Key words: Cre recombinase; nestin Cre; Cre genotoxicity; hydrocephalus; cortex; neuronal progenitor cell

\section{Introduction}

Hydrocephalus is a multifactorial brain pathology characterized by increased volume of CSF associated with enlargement of the head, prominence of the forehead, and progressive brain atrophy, affecting approximately one child in 1000 worldwide (Davy and Robinson, 2003). Hydrocephalus is traditionally classified as communicating or noncommunicating. Different procedures have been used to obtain both forms of hydrocephalus in experimental animals: radiation, infection, gene removal, and transgene expression (Aolad et al., 1998; Davy and Robinson, 2003; Crews et al., 2004). However, by and large, the etiology of communicating hydrocephalus is still poorly understood.

The use of Cre/lox recombination allows to define the role of genes in specific tissues at a specific time, bypassing lethal or

Received May 27, 2005; revised Aug. 3, 2006; accepted Aug. 3, 2006.

We thank Dr.P. Chambon for the Cre-ER ${ }^{\mathrm{T}}{ }^{\mathrm{C} D N A}$, Dr. G. Enikolopov for the nestin promoter/enhancer cassette, Dr. Ferdinando Rossi for critical reading of this manuscript, Dr. Silvio Aime for sharing the NMR facility, Dr. Marco Forni for technical assistance, and Giuseppe Lattanzio for his intellectual help.

Correspondence should be addressed to Paolo Forni, Department of Anatomy, Pharmacology, and Forensic Medicine, University of Turin, Corso Massimo D’Azeglio 52, 10126 Turin, Italy. E-mail: paolo.forni@unito.it. DOI:10.1523/JNEUROSCI.2815-06.2006

Copyright $\odot 2006$ Society for Neuroscience $\quad$ 0270-6474/06/269593-10\$15.00/0 severe developmental defects resulting from their systemic ablation (Kos, 2004). Studies on cultured cells lacking exogenous loxP sites have shown that Cre recombinase can cause decreased growth, cytopathic effects, and chromosomal aberrations (Loonstra et al., 2001; Pfeifer et al., 2001). However, no evidence has been provided for a Cre-induced phenotype in vivo, besides a recent report showing a Cre-related phenotype in plants (Baba et al., 2005) and a transgenic mouse line in which male sterility was shown to arise from high level of Cre expression in spermatids (Schmidt et al., 2000). Nestin is an intermediate filament protein abundantly expressed by neuronal precursors, radial glia, and ependymal cells of the CNS (Mignone et al., 2004). The 5 ' region of the nestin gene has been well characterized, and different intronic elements have been identified (Mignone et al., 2004). Constructs based on the nestin promoter and its second intronic enhancer to direct $\mathrm{Cre}$ transcription have been used to generate transgenic mice expressing a form of Cre, including a nuclear translocation signal (NLSCre) in the CNS (Betz et al., 1996). It was reported that two of the resulting mouse lines, defined as balancer 2 (Bal2) and Bal3, occasionally developed a severe form of hydrocephalus, lethal within the first month of life (Betz et al., 1996). This phenotype did not seem to arise in animals of an 

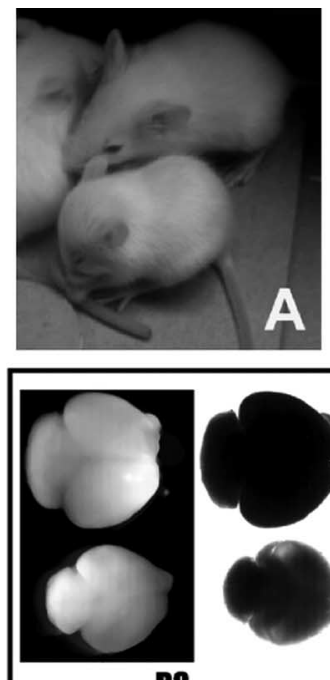

P8
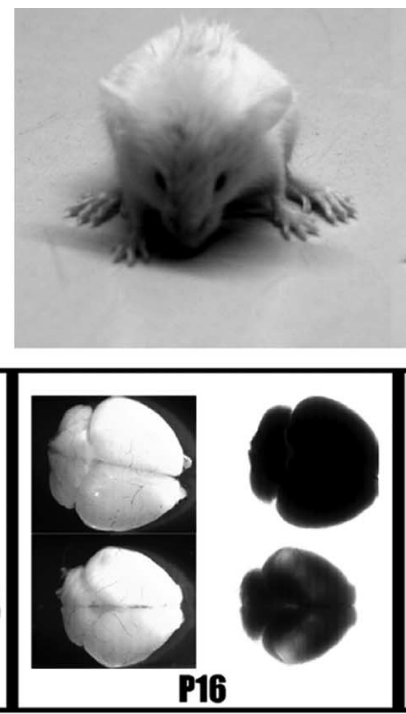

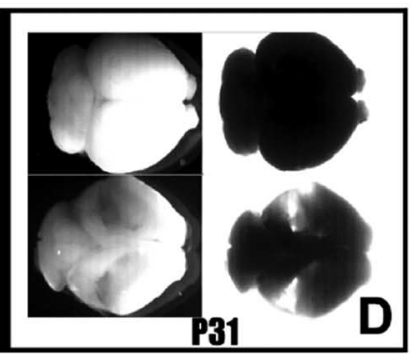

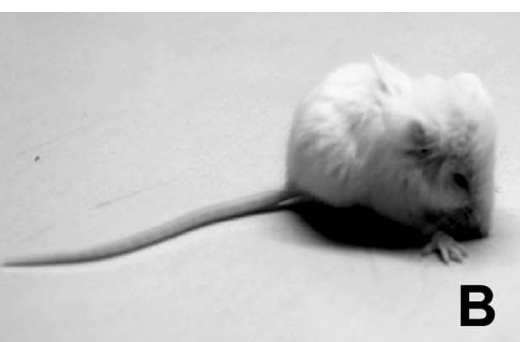

B

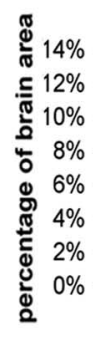

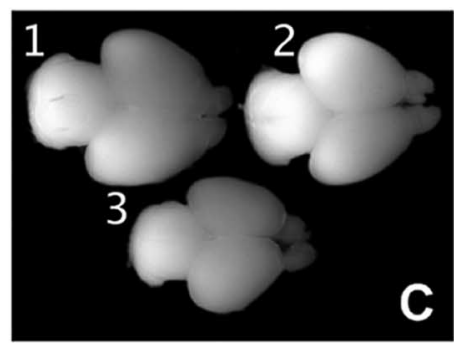

Extent of ventricular dilation

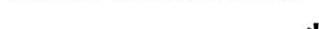

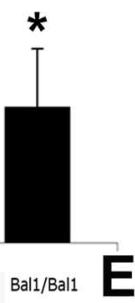

Figure 1. Bal1 nestin Cre homozygous mice (atP14 in the picture) are smaller than their wild-type littermates $(\boldsymbol{A})$, have an enlarged head, and display postural defects ( $\boldsymbol{B}$ ). $\boldsymbol{C}$, Whole brains of $E 19.5$ wild-type (WT) (1), Bal1 nestin Cre heterozygous (2), and Bal1 nestin Cre homozygous (3) embryos. D, Brains of Bal1 nestin Cre homozygous mice at the indicated postnatal age (bottom row) are significantly smaller with respect to those of control wild-type littermates (top row) and display progressive ventricular enlargement. Brains are shown in normal light (dark field) and transilluminated (bright field). $\boldsymbol{E}$, The extent of ventricular dilation at E19.5 is expressed as percentage of brain area occupied by the ventricles. Measurements were done as indicated in Materials and Methods. Error bars represent mean $\pm S D ; n=5$ for each genotype. ${ }^{*} p<0.001, t$ test.

independent line, named Bal1, obtained by using a different construct (Betz et al., 1996).

Here we show that bringing Bal1 nestin NLSCre mice in the homozygous state (and thus doubling the level of Cre in the nucleus of nestin-expressing cells) results in a highly penetrant form of communicating hydrocephalus. This phenotype is attributable to impaired proliferation and increased death of neuronal progenitors caused by Cre genotoxicity.

To strengthen our conclusion, we extended our analysis to two additional transgenic lines in which the nestin promoter drives the expression of a Cre recombinase fused with a truncated estrogen receptor $\left(\mathrm{CreER}^{\mathrm{T} 2}\right)$. In this model, CreER translocates into the nucleus during tamoxifen treatment (Indra et al., 1999). The two independent lines differed in the level of CreER expression. In both models, hydrocephaly appeared in heterozygous embryos, only after tamoxifen treatment albeit at different dosages. Furthermore, the CNS morphological and cellular lesions induced by the treatment were essentially overlapping with those of homozygous Ball embryos. Together, the results obtained with these three models unequivocally link development of hydrocephalus to high levels of nuclear Cre activity in neurogenic cells.

\section{Materials and Methods}

Histology. Animals were anesthetized and transcardially perfused with $4 \%$ paraformaldehyde in PBS. Brains were postfixed overnight at $4^{\circ} \mathrm{C}$, washed in PBS, dehydrated, and paraffin embedded according to standard protocols. Samples were sliced at $12 \mu \mathrm{m}$ on a sliding microtome (Leica, Nussloch, Germany) and mounted on Superfrost Plus slides.

Area calculations. Areas of the brains and ventricles were calculated using the public NIH ImageJ $1.36 \mathrm{~b}$ software on comparable $12 \mu \mathrm{m}$ sections taken at the same anteroposterior level photographed at $5 \times$ magnitude. The ratio between ventricles and total brain areas was expressed in percentage. The ventricular area was the sum of the areas of the two lateral and the third ventricles. The value for each brain was calculated as the mean of the values obtained from three serial sections. Student's $t$ test was used to asses statistical significance between groups.

$B r d U$. Timed-pregnant females were given intraperitoneal injections of 5-bromo-2-deoxyuridine (BrdU) in sterile PBS $(100 \mu \mathrm{g} / \mathrm{g}$ body
Table 1. Frequency of microencephaly/hydrocephalus in the progeny of Bal1 heterozygous crosses

\begin{tabular}{llr}
\hline Genotype & Microencephaly/hydrocephalus & $n$ \\
\hline Bal1/Bal1 & $100 \%$ & 54 \\
Bal1/WT & $0 \%$ & 116 \\
WT & $0 \%$ & 56 \\
\hline
\end{tabular}

Microencephaly was determined by gross observation within the first month of age. The presence of hydrocephalus was verified by transillumination of whole brains or by histological sections. WT, Wild type. $<. />$

weight) at embryonic day 19.5 (E19.5). At $4.5 \mathrm{~d}$ after injection, pups were killed and the brains were processed for immunostaining.

Immunohistochemistry and immunofluorescence. Sections were rehydrated and, for all staining, processed, except for BrdU staining, with four antigen retrieval cycles of $5^{\prime}$ each in a microwave oven $(800 \mathrm{~W})$ in citrate buffer, $\mathrm{pH}$ 6. After blocking for $1 \mathrm{~h}$ at room temperature (RT) with $0.1 \%$ Triton X-100 and 10\% normal serum in PBS, the sections were incubated with primary antibodies in the same solution at RT overnight. Primary antibodies were added at a dilution of 1:300 for anti-Cre recombinase (Novagen, Madison, WI), 1:200 for anti-nestin (Chemicon, Temecula, CA), 1:500 for anti-Ki-67 (Novocastra, Newcastle, UK), and anti-MBP (Immunological Sciences). For BrdU immunolabeling, rehydrated sections were incubated in $2 \mathrm{~N} \mathrm{HCl}$ for $30 \mathrm{~min}$ at $37^{\circ} \mathrm{C}$, rinsed in $0.1 \mathrm{M}$ sodium borate, $\mathrm{pH} 8.3$, and incubated overnight with anti-BrdU monoclonal antibody (Sigma, St. Louis, MO) at a dilution of 1:100. For immunofluorescence, secondary cyanine 3- or FITC-conjugated anti-rabbit or anti-mouse (Sigma) were used at a dilution of 1:300.

For immunohistochemistry, the sections were further processed with biotinylated secondary antibodies (1:500) and the avidin-biotin-peroxidase complex (ABC; Vector Laboratories, Burlingame, $\mathrm{CA}$ ) and finally visualized with DAB (Roche, Mannheim, Germany).

Quantifications. To quantitate differences between the mutant and control littermate brains, comparable transverse brain sections were examined with a Leica DMR light microscope. BrdU-positive cells in cortical plate were counted on digital pictures (20× magnitude) through the whole cortical margin in a grid spanning $150 \mu \mathrm{m}$ under the pial surface, using NIH ImageJ 1.36b software. The value of BrdU-positive cells for each section was the sum of all BrdU-positive cells counted (three sections per animal). Values are given as the mean of the values obtained from three animals for each group. Counts of cleaved caspase-3-positive cells in the cortical plate and pyknotic nuclei in cerebellum were manu- 

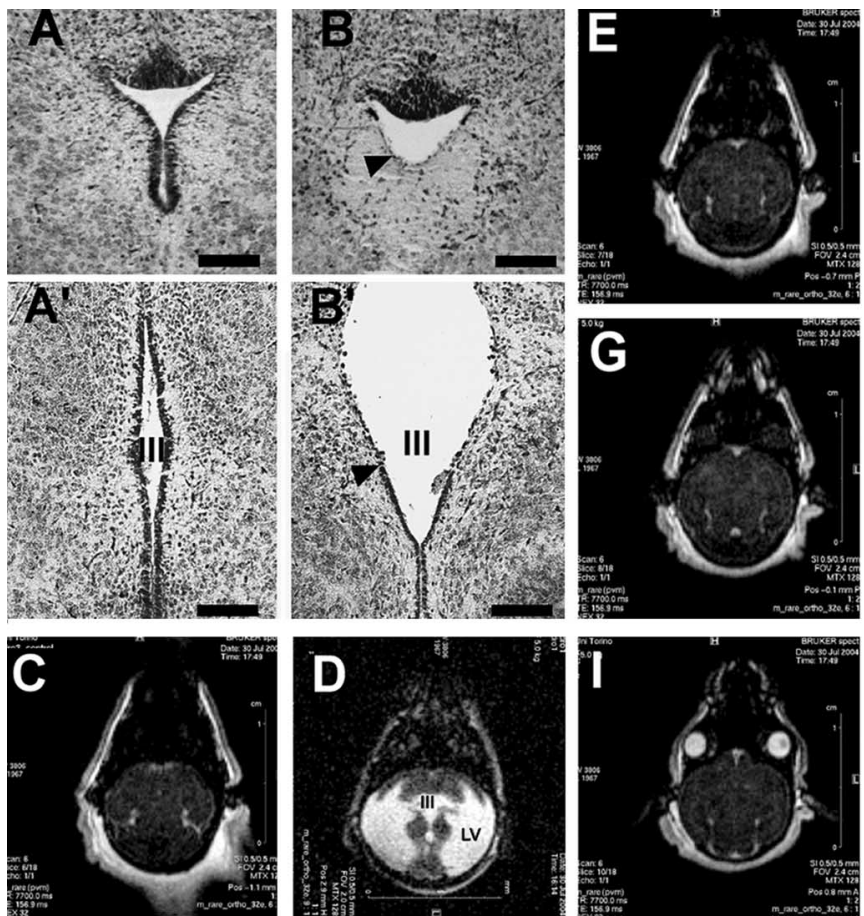

Figure 2. $\quad \boldsymbol{A}, \boldsymbol{B}$, Cresyl violet staining of coronal sections trough the superior colliculi from wild-type $(\boldsymbol{A})$ and homozygous ( $\boldsymbol{B})$ Bal1 nestin Cre mice at P6. In homozygous Bal1 nestin Cre mice, the Sylvius aqueduct is pervious but displays defects in ependymal lining (arrowhead; $\boldsymbol{B})$. Cresyl violet staining of coronal brain sections from wild-type $\left(\boldsymbol{A}^{\prime}\right)$ and homozygous $\left(\boldsymbol{B}^{\prime}\right)$ Bal1 nestin (re mice at P6 show defects in ependymal lining (arrowhead) and in the third ventricle (III). MRI analysis (horizontal sections) of wild-type $(\boldsymbol{C}, \boldsymbol{E}, \boldsymbol{G}, \boldsymbol{I})$ and homozygous $(\boldsymbol{D}, \boldsymbol{F}, \boldsymbol{H}, \boldsymbol{L})$ Bal1 nestin Cre littermates at P6 shows enlargement of the lateral (LV), third (III), and fourth (IV) ventricles. Although there are no obvious signs of obstruction, the Sylvius aqueduct (SA; $\boldsymbol{F}$ ) appears dilated. Scale bars: $\boldsymbol{A}, \boldsymbol{B}, 50 \mu \mathrm{m} ; \boldsymbol{A}^{\prime}, \boldsymbol{B}^{\prime}, 100 \mu \mathrm{m}$.

ally performed with a Leica DMR light microscope at $20 \times$ magnitude on three serial sections per brain. Values were given as the total of pyknotic nuclei or Ki-67-positive cells per section (three animal for each genotype/ treatment). For Ki-67 quantification, 20 areas $\left(2900 \mu \mathrm{m}^{2}\right)$ adjacent the ventricular zone were counted on digital pictures ( $40 \times$ magnitude) spanning the subventricular zone (SVZ). Counts were performed on three serial sections for each brain (three animals for each genotype/ treatment). Student's $t$ test was used to asses statistical significance for each group.

Western blot analysis. Tissue samples were homogenized using a Dounce homogenizer, on ice, in radioimmunoprecipitation assay buffer (150 mm NaCl, 1\% Nonidet P-40, 0.1\% SDS, 0.5\% deoxycholate, $50 \mathrm{~mm}$ Tris HCl, pH 8.0, 2 mm EDTA, pH 8.0, 0.2 mM PMSF, and 0.5 mm DTT) containing protease inhibitor cocktail (Sigma). Protein concentration was determined using $\mathrm{D}_{\mathrm{c}}$ Protein assay (Bio-Rad, Hercules, CA). Equal amounts $(15 \mu \mathrm{g})$ of protein were separated on $12 \%$ SDS-PAGE and transferred to polyvinylidene difluoride membranes. Blots were decorated with anti-Cre rabbit polyclonal antibody (Novagen), monoclonal anti-tubulin (Sigma), and monoclonal anti-p-21 (Santa Cruz Biotechnology, Santa Cruz, CA) according to standard methods. Visualization was performed by using Super Signal Pico enhanced chemiluminescence (Pierce, Rockford, IL).

Semi-quantitative PCR. PCR was performed according to standard procedures. Briefly, DNA was extracted from mouse tails and digested overnight with $100 \mu \mathrm{g} / \mathrm{ml}$ Proteinase $\mathrm{K}$ (Sigma) at $56^{\circ} \mathrm{C}$ in lysis buffer containing $1.5 \mathrm{~mm} \mathrm{MgCl}_{2}, 10 \mathrm{~mm}$ Tris, $\mathrm{pH} 8.5,50 \mathrm{~mm} \mathrm{KCl}, 0.01 \%$ gelatin, $0.45 \%$ Tween 20 , and $0.45 \%$ Nonidet P-40. A 645 bp Cre fragment and a $336 \mathrm{bp} \beta$-actin fragment were amplified using the following primers: Cre sense, AGGCGTTTTCTGAGCATACC; Cre antisense, TAGCTGGCTGGTGGCAGATG for Cre fragment; actin sense, TGAGAAGCTGGCCAAAGAGAAGGGTTAC; and actin antisense, GTGACCTGTTACTTTGGGAGTGGCAAGC for $\beta$-actin fragment. Semiquantitative PCR
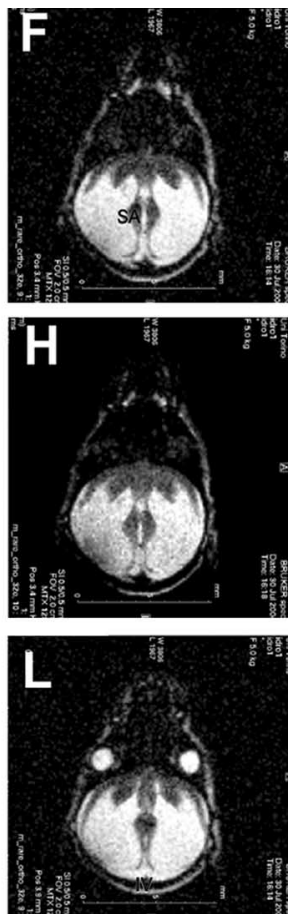

reaction was performed using the following parameters: $94^{\circ} \mathrm{C}$ for $1 \mathrm{~min}, 67^{\circ} \mathrm{C}$ for $30 \mathrm{~s}$, and $72^{\circ} \mathrm{C}$ for $1 \mathrm{~min}$ for 28 cycles using Red-Taq (Sigma). In these conditions, the intensity of Cre versus $\beta$-actin fragment was indicative of homozygous or heterozygous Cre state. Genotyping results were further confirmed by dotblot analysis (data not shown).

Magnetic resonance imaging. Magnetic resonance imaging (MRI) was performed on postnatal day 6 (P6) animals on a vertical 7.05 T system (Avance 300 Wide Bore; Bruker, Newark, DE) equipped with an in vivo microimaging probe head and animal handling unit.

Multislice RARE images were acquired using the following settings: repetition time, $7.7 \mathrm{~s}$; echo time, 3.2 ms; RARE factor, $128 ; n=32$ repetitions; $128 \times 128$ matrix; slice thickness, $0.5 \mathrm{~mm}$; and field of view, $20 \times 20 \mathrm{~mm}$.

Cell preparation and karyotype analysis. Timed-pregnant females were killed by cervical dislocation, and the embryos were removed at E12.5. Dissected hemispheres were incubated in $10 \%$ FBS high-glucose DMEM supplemented with $50 \mathrm{ng} / \mathrm{ml}$ fibroblast growth factor-2 (Invitrogen, Carlsbad, CA), $100 \mathrm{ng} / \mathrm{ml}$ IGF-1, and $100 \mathrm{ng} / \mathrm{ml}$ Colcemid (Invitrogen) for $2 \mathrm{~h}$. The hemispheres were then dissociated in single-cell resuspension, subjected to hypotonic swelling in $75 \mathrm{~mm} \mathrm{KCl}$ solution, and fixed in methanol/acetic acid (3:1). Cells resuspended in a drop of fixative were dropped onto humidified, clean glass slides. The slides were stained with 4,6-diamidino-2-phenylindole (DAPI) $(0.3 \mathrm{~g} / \mathrm{ml}$; Sigma) and coverslipped with Mowiol or stained with conventional Giemsa Stain (5\% Giemsa; Sigma), pH 6.88, for $10 \mathrm{~min}$. Individual metaphases were determined from micrographs captured using a $100 \times$ oil-immersion lens (Leica).

Tamoxifen treatment. Pregnant mothers, at E10.5, were subjected to a single intraperitoneal injection of 2 or $8 \mathrm{mg}$ of tamoxifen (T-5648; Sigma) dissolved in corn oil (C-8267; Sigma), whereas controls were injected with corn oil only.

\section{Results}

Bal1 nestin Cre homozygous mice exhibit growth delay, hydrocephalus, tremors, ataxia, and a reduced brain size While breeding nestin Cre Ball mice to bring Cre recombinase on a defined genetic background, we observed that some pups of mixed background, originating from fortuitous crosses among heterozygotes, developed severe hydrocephalus (Fig. 1). Additional crosses among Ball heterozygotes were set up to determine whether the phenotype was linked to homozygosity for nestin Cre and thus to increased level of expression of the Cre transgene. Hydrocephaly in the progeny indeed followed a Mendelian ratio (Table 1). Homozygosity was confirmed by dot blot, test breeding, and semiquantitative PCR (data not shown).

At birth, homozygous pups were easily identifiable because of their small size, tremors, and balance problems. In the first few weeks of life, homozygous Ball nestin Cre mice showed growth delay and increasing disproportion of the head size relative to the whole body, suggestive of hydrocephalus (Fig. 1A,B). Furthermore, they displayed progressive signs of spasticity and severe locomotor defects, and all died within the fifth week. These animals showed microencephaly, and their brain ventricles were enlarged (Fig. 1C,D). In E19.5 Ball homozygotes, the mean increase 
in the brain area occupied by the ventricles was close to eightfold the controls (Fig. 1E).

The hydrocephalus of Ball nestin Cre homozygous mice is of the communicant (nonobstructive) type

To find out whether the hydrocephalus observed in homozygous Bal1 mice resulted from a CSF drainage block, brains of affected and control littermates were serially sectioned. Detailed histological analysis revealed persistence of the Sylvius aqueduct, which was pervious but defective in ependymal lining (Fig. 2A,B). Ependymal denudation is known to be a key event in the etiology of nonobstructive forms of hydrocephalus (Grondona et al., 1996; Jimenez et al., 2001; Wagner et al., 2003; Dominguez-Pinos et al., 2005). Our histological analysis revealed ependymal lining defects at various levels of the aqueduct and in the third ventricle (Fig. $2 A^{\prime}, B^{\prime}$ ). MRI analysis on Ball pups confirmed enlargement of the four ventricles and the nonobstructive nature of the pathology (Fig. 2C-L).

\section{Brain defects in Bal1 nestin Cre homozygous mice}

Atrophy of the periventricular white matter, including the corpus callosum, is a constant finding in hydrocephalic mice (Dobkin, 1978). In P8 homozygous Ball nestin Cre transgenics, the thickness of the cortex was severely reduced, and the cortical layers were less organized than in controls (Fig. $3 A-D$ ). In all homozygous Bal1 mice, the dentate gyrus of the hippocampus was smaller and disorganized (Fig. $3 E, F$ ). The cerebellum was severely underdeveloped as well (Fig. $3 G, H$ ). No obvious defects or abnormalities were detected in the choroid plexus (data not shown). At P18, the loss and disorganization of myelinated axons and the decrease in neuronal cells of the cortex could be clearly visualized in hydrocephalic mice by, respectively, MBP or DAPI staining (supplemental Fig. 1, available at www.jneurosci.org as supplemental material).

\section{A reduced number of neuronal progenitors reaches the cortical plate in Ball nestin Cre homozygous mice}

In some late embryos and newborn Bal1 nestin Cre homozygous mice, in which the lateral ventricles enlargement was still modest, the decrease in brain size and cortex thickness was already significant (Fig. 4A,B). This suggested that the ensuing development of hydrocephalus could be secondary to a reduction in the number of progenitors reaching the cortical plate (Xie et al., 2002; Assadi et al., 2003).

To evaluate the possible differences in proliferation rate of the progenitors in the SVZ, we decorated E19.5 brain sections for the proliferative antigen Ki-67 (Fig. 4C,D). Quantitative analysis revealed an $\sim 30 \%$ reduction in proliferating SVZ precursors in homozygous Ball embryos (Fig. $4 E$ ). We then injected BrdU at the same gestational age (E19.5) but analyzed the brains at P2. This allowed us to evaluate the number of labeled progenitors that reach the cortical plate in $4.5 \mathrm{~d}$ (Fig. $4 \mathrm{~F}-I$ ). Counts of BrdUpositive cells revealed a reduction of $\sim 50 \%$ in homozygous Ball nestin Cre mice compared with controls (Fig. $4 L$ ). Immunofluorescence for Cre protein confirmed that the neuronal progenitors were indeed Cre positive and that their number was reduced in Bal1 nestin Cre homozygous mice with respect to heterozygous littermates (Fig. $4 M, N$ ). The lower number of progenitors that reach the cortical plate does not seem to be attributable to a defect in migration because cresyl violet, BrdU, or Cre labeling did not show abnormal accumulation of progenitors along the migratory path.
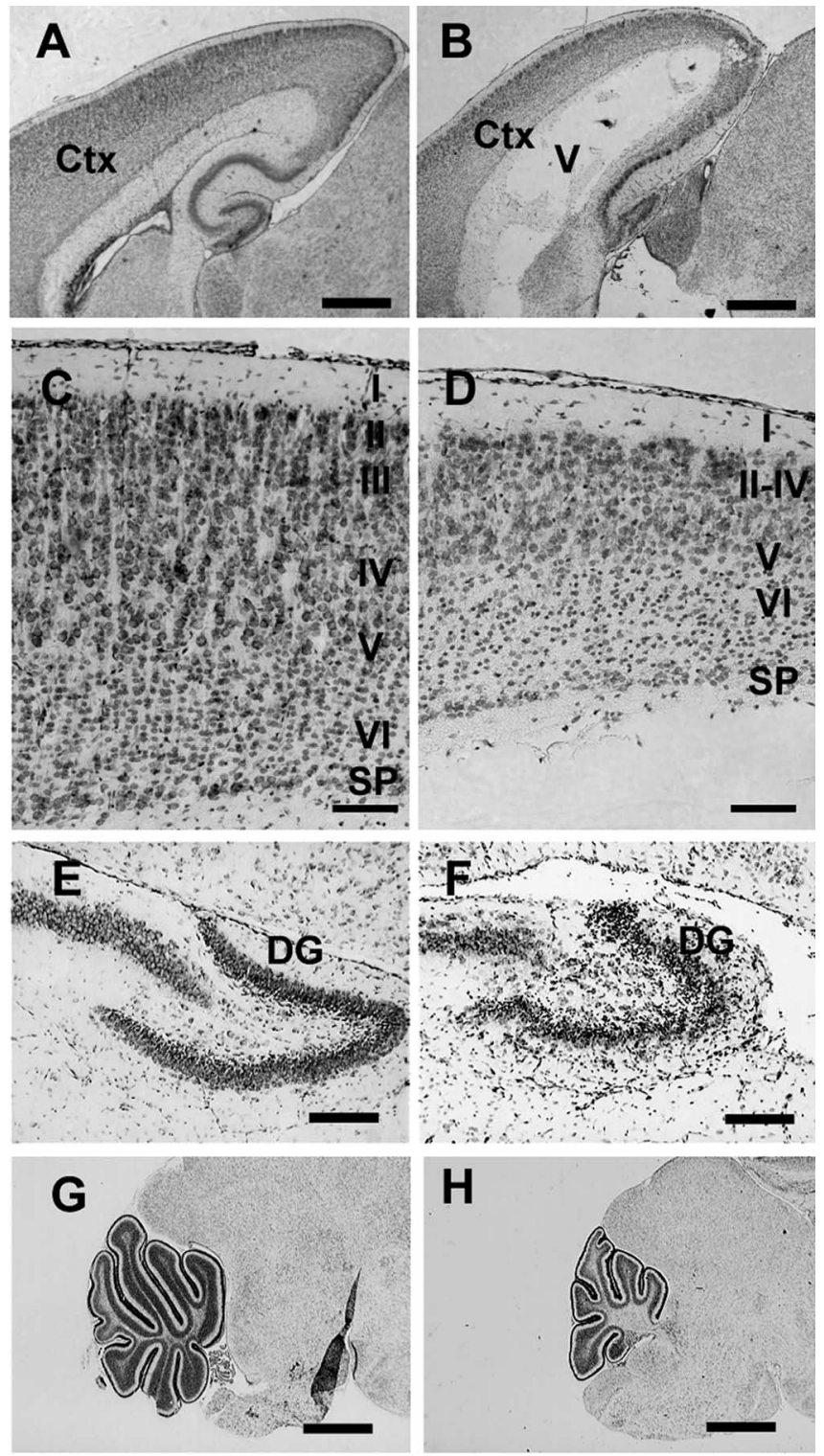

Figure 3. Cresyl violet staining of brain sagittal sections from wild-type $(A, C, E, G)$ and homozygous $(\boldsymbol{B}, \boldsymbol{D}, \boldsymbol{F}, \boldsymbol{H})$ Bal1 nestin Cre mice at P8. $\boldsymbol{A}, \boldsymbol{B}$, The thickness of the parieto-occipital cerebral cortex (ctx) is reduced in homozygous Bal1 nestin Cre mice. $\boldsymbol{C}, \boldsymbol{D}$, Higher magnification shows reduced cellularity and reduced organization of the cortical layers (I-VI) in the occipital cortex. SP, Subplate. The dentate gyrus (DG) of the hippocampus is reduced and less organized $(\boldsymbol{E}, \boldsymbol{F})$ and the cerebellum is underdeveloped $(\boldsymbol{G}, \boldsymbol{H})$ in homozygous Bal1 nestin Cre mice. Scale bars: $A, B, G, H, 500 \mu \mathrm{m} ; C-F, 100 \mu \mathrm{m}$.

\section{Apoptosis is increased in the developing cortex and} cerebellum of Ball nestin Cre homozygous mice

Because the reduction in neuronal progenitors seemed to be more dramatic in the cortical plate than in the SVZ, we verified whether apoptosis occurred during migration. Cleaved caspase 3 staining of E19.5 brain sections revealed an increase in apoptotic cells in the intermediate zone and in the cortical plate of homozygous Bal1 nestin Cre embryos compared with controls (Fig. $5 A, B)$. Cleaved caspase-3-positive cell counts in the cortical plate showed a $35 \%$ increase of apoptosis, indicating that a significant number of cells undergoes cell death after leaving the SVZ. Accordingly, analysis of postnatal sections of cerebellum at P2 also revealed an increase in cleaved caspase-3-positive cells (Fig. $5 D, E)$ and a $39 \%$ increase of pyknotic nuclei compared with controls (Fig. 5D-F). 


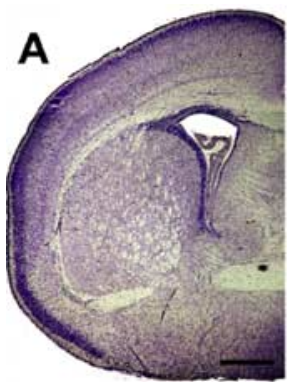

B
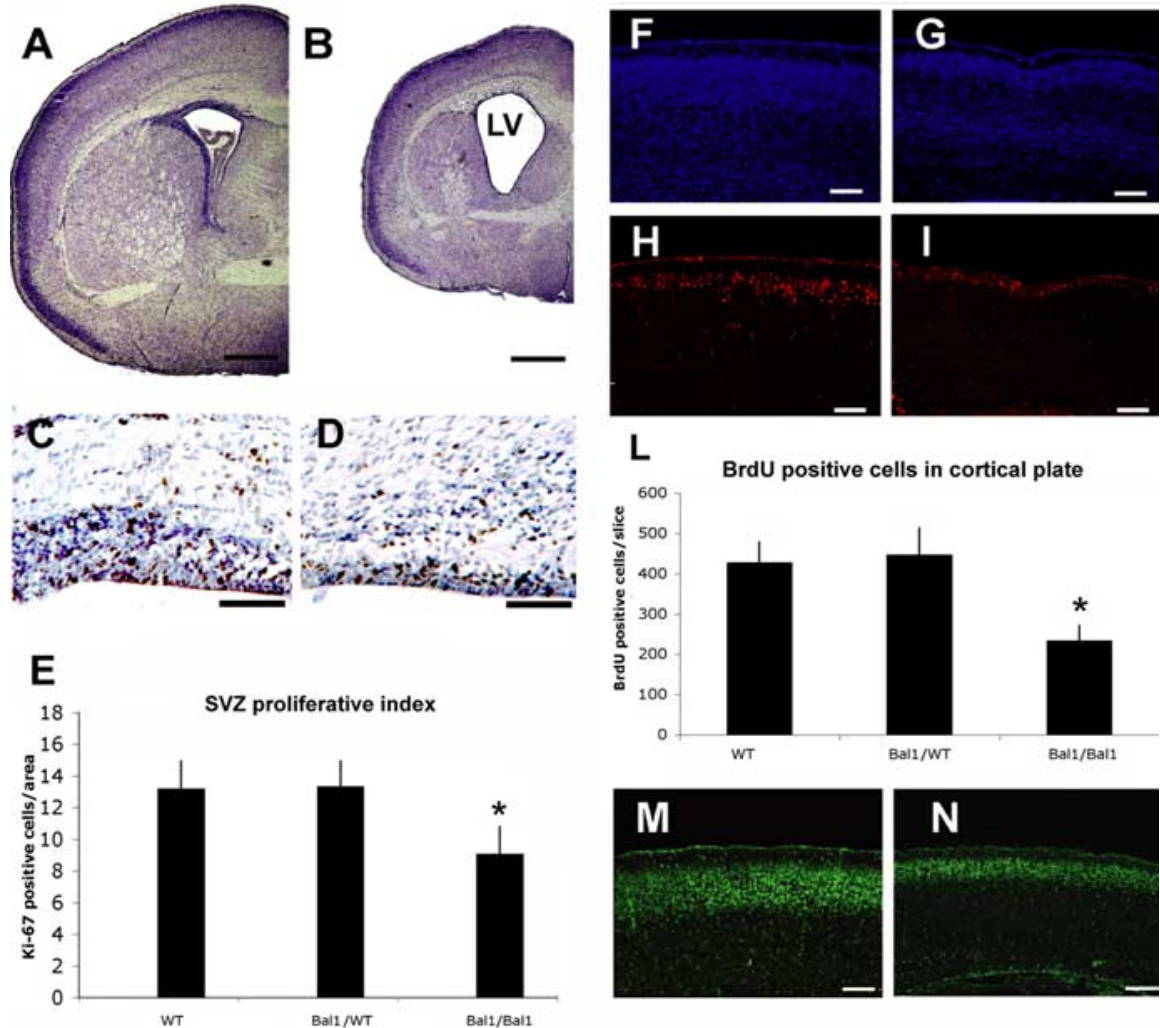

\begin{abstract}
L
\end{abstract}
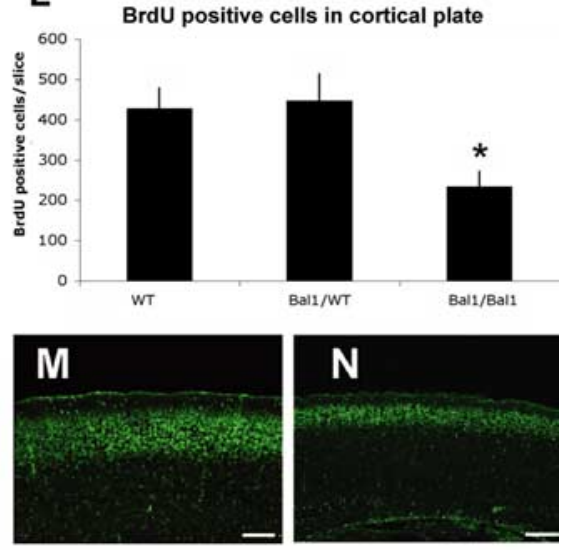

Figure 4. $\quad A, B$, Cresyl violet staining of brain coronal sections from wild-type $(A)$ and homozygous ( $B)$ Bal1 nestin Cre littermates at P2. LV, Lateral ventricles. C, D, Ki-67 staining at E19.5 shows reduction of positive cells in the SVZ of homozygous Bal1 nestin Cre mice (D) compared with wild-type littermates ( $\boldsymbol{C}$. $\boldsymbol{E}$, Quantification of Ki-67-positive cells in the SVZ of homozygous Bal1 and heterozygous and wild-type controls (WT) (see Material and Methods; $n=3$ ). $\boldsymbol{F}-\mathbf{I}$, BrdU staining of the cortex of P2 newborn mice analyzed $4.5 \mathrm{~d}$ after injection of pregnant mothers. BrdU-positive cells in the cortex of Bal1 nestin Cre homozygotes (I) are significantly reduced compared with wild-type controls $(\boldsymbol{H}) . \boldsymbol{F}, \mathbf{G}, \mathrm{DAPI}$ staining. L, Quantification of BrdU-positive cells in the cortical plate of $P 2$ animals of the same litter $4.5 \mathrm{~d}$ after injection. $M, N$, Cre immunostaining of the pial layers of the cortex in P2 homozygous Bal1 nestin Cre mice $(\boldsymbol{N})$ and heterozygous littermates $(\boldsymbol{M})$ reveals a reduction of Cre-positive progenitors that have reached the cortex. $E-L, n=3$ for each genotype; values are mean $\pm S D .{ }^{*} p<0.001, t$ test. Scale bars: $\boldsymbol{A}, \boldsymbol{B}, 500 \mu \mathrm{m} ; \boldsymbol{C}, \boldsymbol{D}$, $50 \mu \mathrm{m} ; \boldsymbol{F}, \mathbf{G}, \boldsymbol{H}, \boldsymbol{I}, \boldsymbol{M}, \boldsymbol{N}, 100 \mu \mathrm{m}$.

\section{Cre recombinase under nestin promoter control is expressed in neuronal progenitors}

All of the abnormalities observed in the Ball nestin Cre line involved neurogenic areas of the brain. To link the observed effects with the activity of Cre recombinase, we verified in heterozygous Bal1 nestin Cre mice whether Cre recombinase was coexpressed with nestin in these districts. Immunofluorescence showed that Cre recombinase and nestin are both expressed in the subventricular zone of the cortex, in the ependyma, in the dentate gyrus of the hippocampus, and in cerebellar granule cell precursors (supplemental Fig. 2, available at www.jneurosci.org as supplemental material). Interestingly, in all of these districts, particularly high levels of Cre recombinase positivity were found in the nuclei of postmitotic cells. Evidently, Cre is stable for days and, given the presence of an NLS signal, progressively translocates into the nucleus.

\section{Increased levels of NLSCre and aneuploidy in brain of Ball homozygotes}

The level of Cre recombinase was evaluated in whole brain of homozygous and heterozygous Ball pups by Western blot, normalizing the samples for total protein content. Despite the intrinsic loss of brain tissue, relatively higher levels of Cre recombinase were found in the brain of homozygous mice than in the brain of heterozygous littermates (supplemental Fig. 3, available at www.jneurosci.org as supplemental material). One of the effects of high levels of Cre recombinase in the nucleus is an increased incidence of genomic damage with consequent aneuploidy (Loonstra et al., 2001). Karyotype analysis of cells obtained from developing brains of E12.5 embryos revealed that the percentage of aneuploid cells in homozygous Ball embryos was almost twice as much as that of the wild-type controls (Table 2). The small increase of aneuploidy in heterozygous embryos was not significant. Conversely, the relatively high level of "physiological" aneuploidy observed in developing control brains is in line with the values reported in previous work (Rehen et al., 2001; Kaushal et al., 2003).

\section{The nestin CreER ${ }^{\mathrm{T} 2}$ models}

To unequivocally establish whether the phenotype observed in Ball mice was indeed attributable to the activity of Cre recombinase into the nucleus, we analyzed two recently generated independent lines of nestin Cre transgenics, nestin CreER ${ }^{\mathrm{T} 2}$ line 1 and 4 (Imayoshi et al., 2006). In these transgenics, the nestin promoter controls expression of a Cre recombinase fused with the mutated ligand-binding domain of the human estrogen receptor (Feil et al., 1996; Indra et al., 1999). Nestin Cre$\mathrm{ER}^{\mathrm{T} 2}$ mice represent a perfect control for the specificity of the Cre genotoxic effect, because Cre is already expressed before tamoxifen treatment, but its nuclear localization is greatly enhanced by the treatment (Loonstra et al., 2001; Hayashi and McMahon, 2002). The two mouse lines express different levels of Cre protein. Line 1 is a high expresser, whereas line 4 expresses a lower level of Cre (Imayoshi et al., 2006). Crossings with ROSA26 Cre reporter mice (Soriano, 1999) have shown that a basal level of Cre recombinase is present in the cell nuclei of untreated animals of line 1 , whereas very low basal activity has been observed in line 4 (Imayoshi et al., 2006). The basal level of nuclear Cre observed in lines 1 and 4, sufficient to determine LoxP-mediated recombination (Imayoshi et al., 2006), does not result in a phenotype. In fact, all untreated nestin CreER ${ }^{\mathrm{T} 2}$ mice are normal.

Crossings of CreER ${ }^{\mathrm{T} 2}$ heterozygous mice of both lines 1 and 4 with wild-type animals were set up, and some pregnant mothers (E10.5) were treated with $2 \mathrm{mg}$ of tamoxifen, whereas others, treated with vehicle alone, were used as controls. Embryos were analyzed at E19.5. A high percentage of line 1 heterozygous Cre$\mathrm{ER}^{\mathrm{T} 2}$ embryos treated with $2 \mathrm{mg}$ of tamoxifen during pregnancy showed dramatic reduction of brain and cerebellar size and ventricular dilation with ependymal defects (Table 3, Fig. 6) (supplemental Fig. 4, available at www.jneurosci.org as supplemental material). Conversely, the embryos treated with $2 \mathrm{mg}$ of tamoxifen or the oil- or tamoxifen-treated wild-type controls were all normal. Because line 1 is a high expresser whereas line 4 expresses Cre at much lower levels (Imayoshi et al., 2006), we decided to evaluate whether a higher tamoxifen dosage could give rise in the 

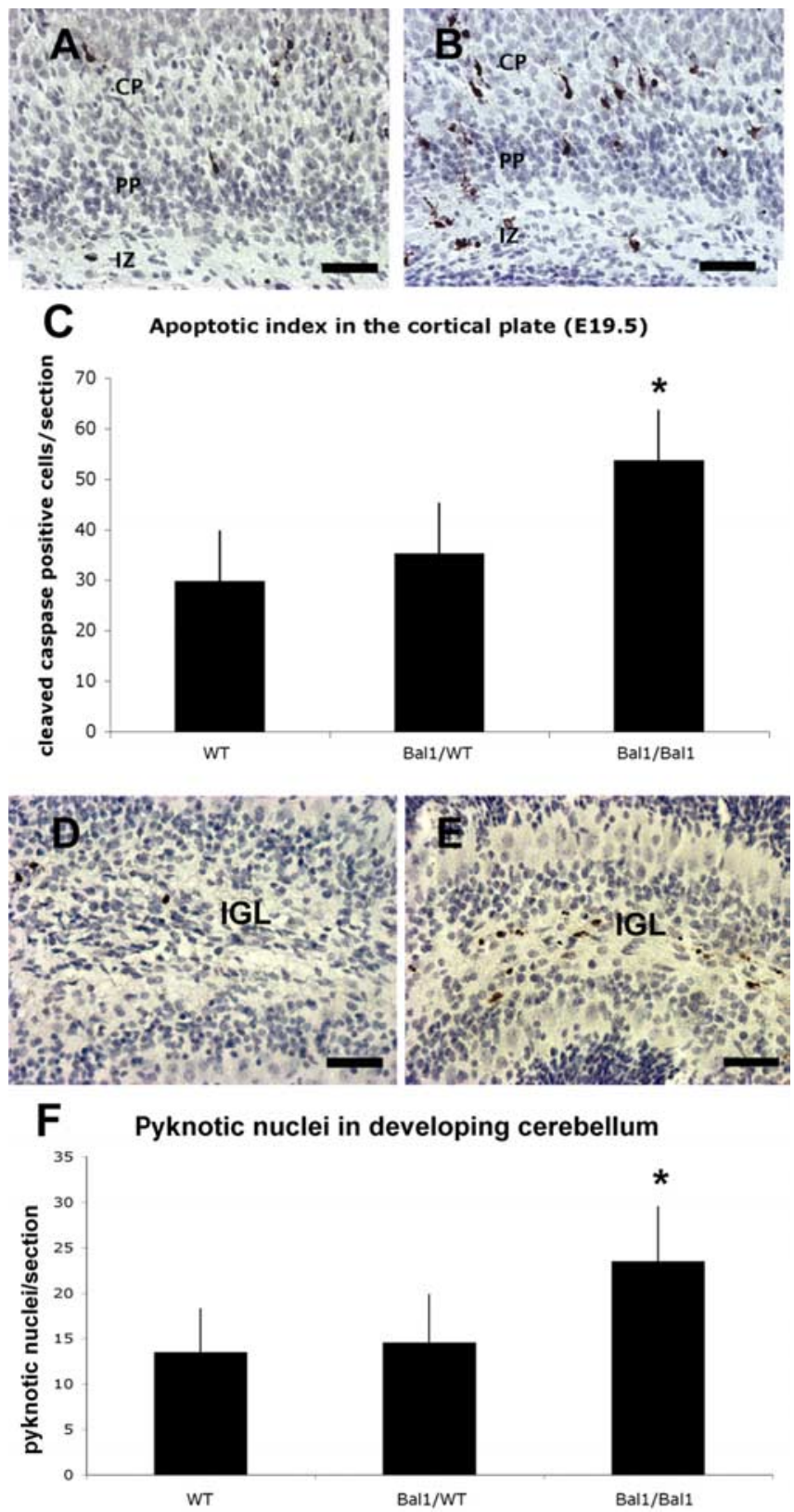

Figure 5. Immunostaining for cleaved caspase-3 on E19.5 wild-type $(\boldsymbol{A})$ and homozygous (B) Bal1 nestin (re brain sections reveals an increased number of cells undergoing apoptosis in the intermediate zone (IZ), throughout the pre-plate (PP), and in the cortical plate (CP). C, Quantification of cleaved caspase-3 in developing cortex (E19.5). Immunostaining for cleaved caspase-3 on sections of $\mathrm{P} 3$ wild-type (WT; $\boldsymbol{D}$ ) and homozygous $(\boldsymbol{E})$ Bal1 nestin Cre cerebellum sections shows an increased number of cleaved caspase-3-positive cells in the inner granule layer (IGL) of homozygous Bal1 nestin (re mice (E). $\boldsymbol{F}$, Quantification of pyknotic nuclei in cerebellum after cresyl violet staining on $P 2$ pups of the same litter. $n=3$ for each genotype; values are mean $\pm S D .^{*} p<0.001, t$ test $(\boldsymbol{C}, \boldsymbol{F})$. Scale bars, $50 \mu \mathrm{m}$.

Table 2. Chromosomal aneuploidy in isolated embryonic (E12.5) neuroblast spreads of control (WT/WT), heterozygous (Bal1/WT), and homozygous (Bal1/Bal1) embryos revealed by Giemsa staining

\begin{tabular}{lll}
\hline Genotype & Number of spread examined & \% Aneuploid \\
\hline WT & 153 & $35 \pm 4$ \\
Bal1/WT & 156 & $42 \pm 9^{*}$ \\
Bal1/Bal1 & 173 & $69 \pm 7^{* *}$ \\
\hline
\end{tabular}

$n=3$ for each genotype; ${ }^{*} p>0.1, \chi^{2}$ test; ${ }^{* *} p<10^{-10}, \chi^{2}$ test. WT, Wild type.
Table 3. Frequency of microencephaly/hydrocephalus in CreER ${ }^{\mathrm{T} 2}$ embryos (line 1 and line 4) after indicated treatment at E10.5

\begin{tabular}{|c|c|c|c|}
\hline Mouse line & Treatment at E10.5 & Microencephaly/hydrocephalus & $n$ \\
\hline CreER ${ }^{\mathrm{T2}}$ line $1^{+/-}$ & $2 \mathrm{mg}$ of tamoxifen & $77 \%$ & 22 \\
\hline $\mathrm{CreER}^{\mathrm{T2}}$ line $1^{+/-}$ & Vehicle & $0 \%$ & 40 \\
\hline CreER $^{T 2}$ line $4^{+/-}$ & $8 \mathrm{mg}$ of tamoxifen & $83 \%$ & 12 \\
\hline CreER $^{\mathrm{T2}}$ line $4^{+/-}$ & $2 \mathrm{mg}$ of tamoxifen & $0 \%$ & 3 \\
\hline CreER $^{T 2}$ line $4^{+/-}$ & Vehicle & $0 \%$ & 6 \\
\hline WT & $8 \mathrm{mg}$ of tamoxifen & $0 \%$ & 8 \\
\hline WT & $2 \mathrm{mg}$ of tamoxifen & $0 \%$ & 40 \\
\hline WT & Vehicle & $0 \%$ & 48 \\
\hline
\end{tabular}

Microencephaly was determined by gross observation at E19.5. The presence of hydrocephalus was verified by transillumination of whole brains or by histological sections. WT, Wild type.

latter to the phenotype observed in line 1 . For this purpose, we treated heterozygous line 4 pregnant mothers (E10.5) with a single injection of $8 \mathrm{mg}$ of tamoxifen. As reported by others, we observed an increase in the incidence of abortions at this dosage (Hayashi and McMahon, 2002). However, analysis of the surviving embryos at E19.5 revealed no brain defects in tamoxifentreated wild-type controls. Conversely, in heterozygous embryos of the CreER ${ }^{\mathrm{T} 2}$ line $4,8 \mathrm{mg}$ of tamoxifen produced a phenotype essentially overlapping with that described previously for homozygous Ball mice and tamoxifen-treated $(2 \mathrm{mg})$ heterozygous CreER $^{\mathrm{T} 2}$ line 1 animals (Fig. 7, Table 3) (supplemental Fig. 4, available at www.jneurosci.org as supplemental material). The somehow lower frequency of hydrocephalus observed in the two inducible CreER ${ }^{\mathrm{T} 2}$ lines with respect to homozygous Bal1 mice is likely to be attributable to variability in the efficacy of the tamoxifen treatment.

\section{Defects in neuronal precursors after tamoxifen treatment}

To verify whether the cellular defects underlying the development of the brain phenotype in homozygous Ball mice were detectable also in the tamoxifen-treated heterozygous $\mathrm{CreER}^{\mathrm{T} 2}$ lines, we duplicated the analysis of proliferation and apoptosis in the new animal models. Visualization of proliferating cells by Ki-67 staining in tamoxifen-treated E19.5 CreER ${ }^{\mathrm{T} 2}$ brain slices showed that the number of proliferating cells in the SVZ and intermediate zone was dramatically reduced (Fig. $8 A, B$ ). Counting of Ki-67-labeled cells showed that the reduction of cycling cells in the SVZ/intermediate zone of tamoxifen-treated embryos compared with controls was of the order of 30\% for line 1 and $50 \%$ for line 4 (when treated at the effective dosage of tamoxifen) (Fig. 8C). Surprisingly, at variance with respect to the homozygous Bal1 model, staining with cleaved caspase- 3 of E19.5 brain slices did not reveal a significant increase in apoptotic cells (data not shown). Because this model is based on transient rather than constitutive nuclear Cre translocation, it is possible that the peak of Cre-induced cell death may occur with a different timing.

\section{Discussion}

Several reports indicate that Cre recombinase might exert toxic effects attributable to recombination of genomic DNA at sites that share only a limited homology with the loxP sequence of bacteriophage P1. These "illegitimate" recombination events can result in DNA strand breaks, chromosome rearrangements, aneuploidy, and alteration in the normal proliferation rate attributable to an accumulation in the $\mathrm{G}_{2}-\mathrm{M}$ phase (Thyagarajan et al., 2000; Loonstra et al., 2001; Pfeifer et al., 2001; Silver and Livingston, 2001).

The present study describes a Cre-induced phenotype characterized by severe reduction of the brain and hydrocephaly. This 


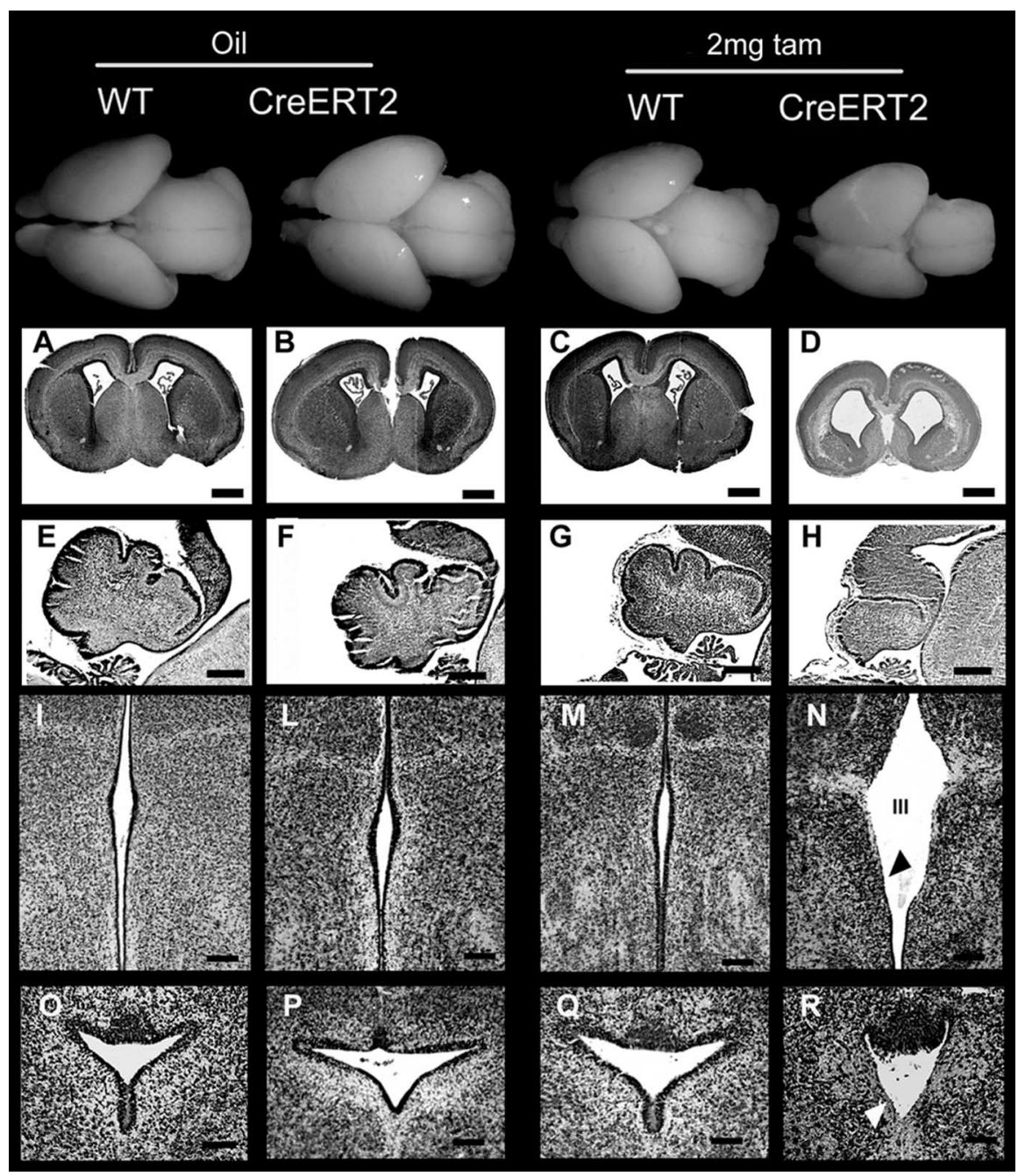

Figure 6. Top row, Wild-type and heterozygous CreER ${ }^{\mathrm{T} 2}$ line 1 whole brains at E19.5 after the indicated treatments. Cresyl violet staining of coronal brain sections $(\boldsymbol{A}-\boldsymbol{D})$, sagittal cerebellar sections $(\boldsymbol{E}-\boldsymbol{H})$, coronal sections of the third ventricle (III) $(\boldsymbol{I}-\boldsymbol{N})$, and coronal sections of the Sylvius aqueduct $(\boldsymbol{O}-\boldsymbol{R})$. Heterozygous nestin (reER ${ }^{\mathrm{T} 2}$ embryos treated with vehicle alone (oil) display normal brain $(\boldsymbol{B})$ and normal cerebellar development $(\boldsymbol{F})$ and are thus indistinguishable from wild-type (WT) controls treated with either oil $(\boldsymbol{A}, \boldsymbol{E})$ or $2 \mathrm{mg}$ of tamoxifen (C, $\boldsymbol{G}$; tam). Tamoxifen-treated heterozygous nestin CreER ${ }^{\mathrm{T} 2}$ display severe signs of microencephaly and ventricular dilation $(\boldsymbol{D})$, reduced development of the cerebellum $(\boldsymbol{H})$, ventricular dilation $(\boldsymbol{D}, \boldsymbol{N}, \boldsymbol{R})$, and defects in ependymal lining of the third ventricle (III) and Sylvius aqueduct (N, $\boldsymbol{R}$, arrows). Scale bars: $\boldsymbol{A}-\boldsymbol{D}, 500 \mu \mathrm{m} ; \boldsymbol{E}-\boldsymbol{H}, 200 \mu \mathrm{m} ; \boldsymbol{I}-\boldsymbol{R}, 100 \mu \mathrm{m}$.

phenotype was observed in three distinct nestin Cre transgenic lines, thus ruling out the possibility that it could be attributable to the insertion site or to cosegregating mutations. In the first model (Ball line), microencephaly and hydrocephaly were found in $100 \%$ of homozygous animals. In this mouse line, the Cre protein, because of the presence of a nuclear localization signal (NLSCre), is constantly localized in the nucleus. Conversely, in the second and third model (CreER ${ }^{\mathrm{T} 2}$ lines 1 and 4 ), the development of hydrocephaly was dependent on tamoxifen, which controls the translocation of the enzyme into the nucleus. Thus, the described effects were not attributable to aspecific toxicity of the Cre protein (ineffective when stored in the cytoplasm) but did depend on its nuclear localization. The requirement for a threshold of Cre in the nucleus was confirmed by the observation that an increase of aneuploidy was observed only in homozygous Ball brains.

The causal link between development of the phenotype and Cre activity was further strengthened by the observation of its dependence on tamoxifen dosage. Whereas in the $\mathrm{CreER}^{\mathrm{T} 2}$ line 1 , a single treatment with $2 \mathrm{mg}$ of tamoxifen at E10.5 was sufficient to induce hydrocephaly, this dosage was without effect in line 4, which expresses CreER recombinase at a lower level (Imayoshi et al., 2006). This, together with the lack of phenotype in tamoxifen-treated wild-type controls, proves that hydrocephaly is not an artifact of the treatment. The fact that hydrocephaly appeared only in homozygosity in the NLSCre Ball line or when increasing the dosage of tamoxifen to $8 \mathrm{mg}$ in the low expresser CreER ${ }^{\mathrm{T} 2}$ line 4 indicates that, to exert its genotoxic effect, the level of nuclear Cre must overcome a critical threshold. It is important to note that, in our models, chronic or transient translocation of Cre in the nucleus of neuronal progenitors was facilitated, via either an NLS or fusion with the ER. It is known that both of these modifications strongly increase nuclear translocation and recombination efficiency but may also cause higher genotoxicity (Loonstra et al., 2001; Baba et al., 2005). This, however, has been observed in cell lines only when the concentration of Cre in the nucleus exceeds a certain threshold (Loonstra et al., 2001; Baba et al., 2005). Accordingly, in NLSCre Bal1 mice, the phenotype appeared only in homozygosity, whereas in the CreER ${ }^{\mathrm{T} 2}$ lines, it was induced only on adequate tamoxifen dosage (Hayashi and McMahon, 2002). Cre genotoxicity may also critically depend on when the cells are exposed to Cre activity. In particular, Cre recombinase is more likely to yield toxic effects during phases of the cell cycle when chromatin is uncondensed and probably more vulnerable to its illegitimate action (Loonstra et al., 2001). Ki-67 staining of brain sections derived from E19.5 NLSCre Bal1 and tamoxifen-treated CreER ${ }^{\mathrm{T} 2}$ embryos showed a significant reduction of the cycling cells in the SVZ. However, heavy Cre labeling in the pial layers of the developing cortex in Ball mice indicates that, once postmitotic, neural cells seem to be able to endure prolonged exposure to Cre without loss of viability.

A plethora of nestin Cre models exists and have been successfully used in the heterozygous state to investigate the role of specific proteins during development. Heterozygous nestin NLSCre Balancer mice have themselves been successfully used to overcome embryonic lethality (Betz et al., 1996; Alonzi et al., 2001; Uno et al., 2003). These models do not generally result in an increase rate of idrocephaly (Tronche et al., 1999; Trumpp et al., 1999; Treutelaar et al., 2003; Thuret et al., 2004; Liu et al., 2005). It should be noted, however, that (except for Ball mice, which were always used in heterozygosity) the constructs described in these works did not include an element to facilitate Cre nuclear translocation.

Nestin Cre-mediated gene inactivation has been successfully applied to genes having key roles in proliferation, survival, or migration (Isaka et al., 1999; Pirvola et al., 2002; Haigh et al., 


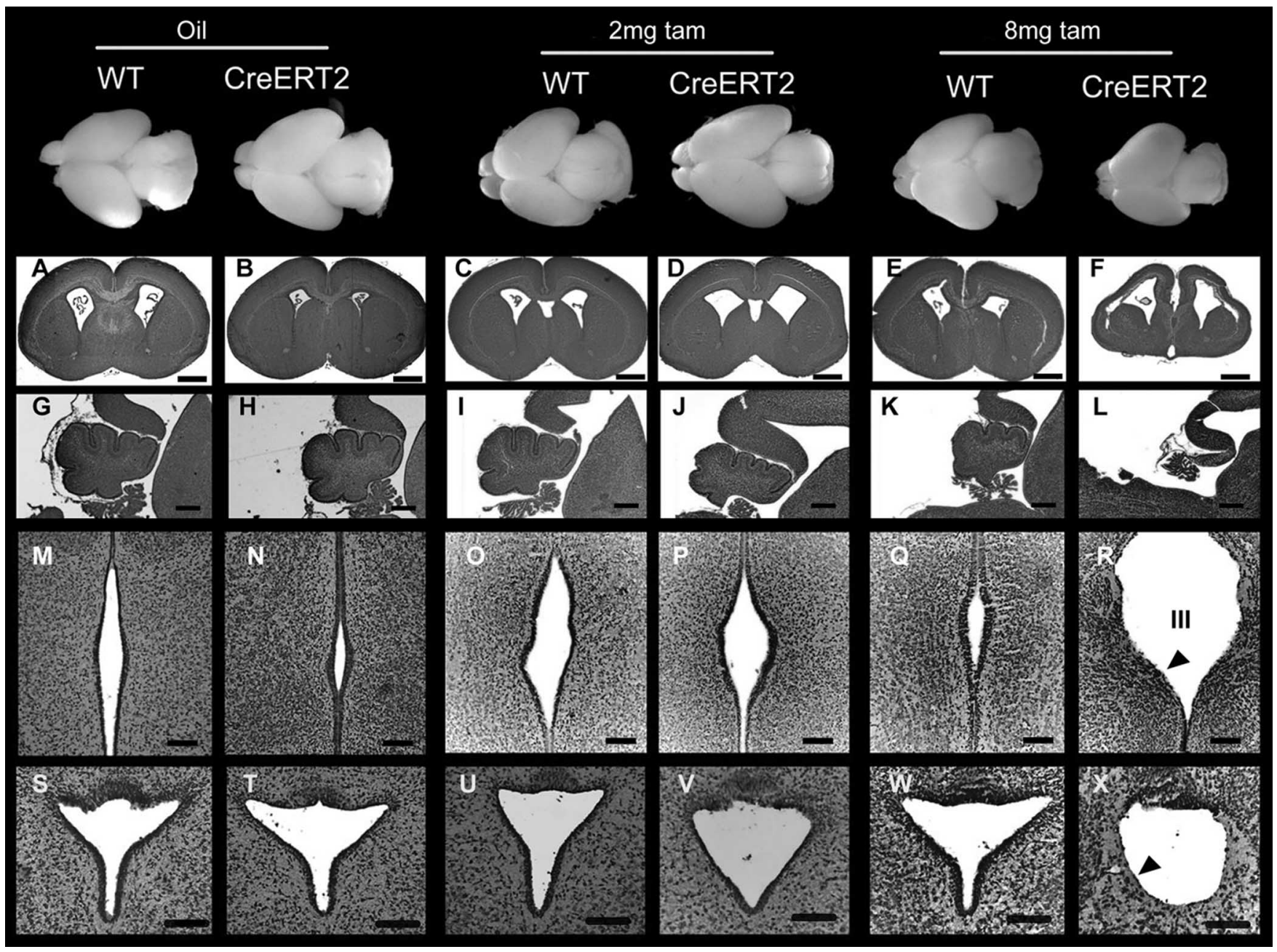

Figure 7. Top row, Wild-type and heterozygous (reER ${ }^{\mathrm{T}}$ line 4 whole brains at E19.5 after the indicated treatments. Cresyl violet staining of coronal brain sections $(\boldsymbol{A}-\boldsymbol{F})$, sagittal cerebellar sections $(\boldsymbol{G}-\boldsymbol{L})$, coronal sections of the third ventricle (III) $(\boldsymbol{M}-\boldsymbol{R})$, and Sylvius aqueduct $(\boldsymbol{S}-\boldsymbol{X})$. Heterozygous nestin $\left(\mathrm{reER}^{\mathrm{T} 2}\right.$ embryos treated with vehicle alone (oil) $(\boldsymbol{B}, \boldsymbol{H}, \boldsymbol{N}, \boldsymbol{T})$ or with $2 \mathrm{mg}$ of tamoxifen $(\operatorname{tam})(\boldsymbol{D}, \boldsymbol{J}, \boldsymbol{P}, \boldsymbol{V})$ are indistinguishable from oil-treated $(\boldsymbol{A}, \boldsymbol{G}, \boldsymbol{M}, \boldsymbol{S})$ and $2 \mathrm{mg}$ tamoxifen-treated $(\boldsymbol{C}, \boldsymbol{I}, \mathbf{O}, \boldsymbol{U})$ wild-type (WT) animals. Tamoxifen-treated $(8 \mathrm{mg})$ wild-type embryos are indistinguishable from the previous controls $(\boldsymbol{E}, \boldsymbol{K}, \boldsymbol{Q}, \boldsymbol{W})$, whereas $8 \mathrm{mg}$ tamoxifen-treated heterozygous nestin $\mathrm{CreER}^{\mathrm{T} 2}(\boldsymbol{F}, \boldsymbol{L}, \boldsymbol{R}, \boldsymbol{X})$ display severe signs of microencephaly and ventricular dilation $(\boldsymbol{F})$, reduced development of the cerebellum $(\boldsymbol{L})$, defects in ependymal lining in the third ventricle $(\boldsymbol{R})$ and defects in Sylvius aqueduct ependymal lining $(\boldsymbol{X})$ (arrowheads). Scale bars: $\boldsymbol{A}-\boldsymbol{F}, 500 \mu \mathrm{m}$; G-L, $200 \mu \mathrm{m} ; M-X, 100 \mu \mathrm{m}$.

2003; Lin et al., 2003; Tomita et al., 2003; Treutelaar et al., 2003; Klezovitch et al., 2004; Raab et al., 2004; Berube et al., 2005). Interestingly, all of the features described in these models as well as in other animal models of impaired neurogenesis, such as specific ablation of radial glia (Xie et al., 2002) or loss-of-function of genes involved in neuronal migration or adhesion (Ramanathan et al., 1996; Fransen et al., 1998; Bearer, 2001; Assadi et al., 2003; Sakata-Haga et al., 2004), were recapitulated at different levels in our homozygous NLSCre Ball mice or in the heterozygous Cre$\mathrm{ER}^{\mathrm{T} 2}$ models. This suggests that impairment of nestin-positive cell populations either by specific genes removal or through Cremediated toxicity may lead to similar defects.

In conclusion, while taking advantage of the Cre/LoxP system, it should be kept in mind that the presence of elements facilitating nuclear translocation or the use of transgenics with high levels of Cre expression can, on one side, ensure high level of recombination, but, on the other, could yield enhanced phenotypes, attributable not only to target gene ablation but also to Cre-mediated genotoxicity. This could be especially true in the CNS, which is a compartment naturally prone to genomic instability (Kim et al., 2001; Rehen et al., 2001; Kaushal et al., 2003; Yang et al., 2003). It is therefore essential to evaluate the phenotypes observed in Cre/ loxP conditional knock-outs against Cre transgenic controls.

\section{References}

Alonzi T, Middleton G, Wyatt S, Buchman V, Betz UA, Muller W, Musiani P, Poli V, Davies AM (2001) Role of STAT3 and PI 3-kinase/Akt in mediating the survival actions of cytokines on sensory neurons. Mol Cell Neurosci 18:270-282.

Aolad HM, Inouye M, Hayasaka S, Darmanto W, Murata Y (1998) Congenital hydrocephalus caused by exposure to low level X-radiation at early gestational stage in mice. Biol Sci Space 12:256-257.

Assadi AH, Zhang G, Beffert U, McNeil RS, Renfro AL, Niu S, Quattrocchi CC, Antalffy BA, Sheldon M, Armstrong DD, Wynshaw-Boris A, Herz J, D'Arcangelo G, Clark GD (2003) Interaction of reelin signaling and Lis1 in brain development. Nat Genet 35:270-276.

Baba Y, Nakano M, Yamada Y, Saito I, Kanegae Y (2005) Practical range of effective dose for Cre recombinase-expressing recombinant adenovirus without cell toxicity in mammalian cells. Microbiol Immunol 49:559-570.

Bearer CF (2001) L1 cell adhesion molecule signal cascades: targets for ethanol developmental neurotoxicity. Neurotoxicology 22:625-633.

Berube NG, Mangelsdorf M, Jagla M, Vanderluit J, Garrick D, Gibbons RJ, Higgs DR, Slack RS, Picketts DJ (2005) The chromatin-remodeling pro- 

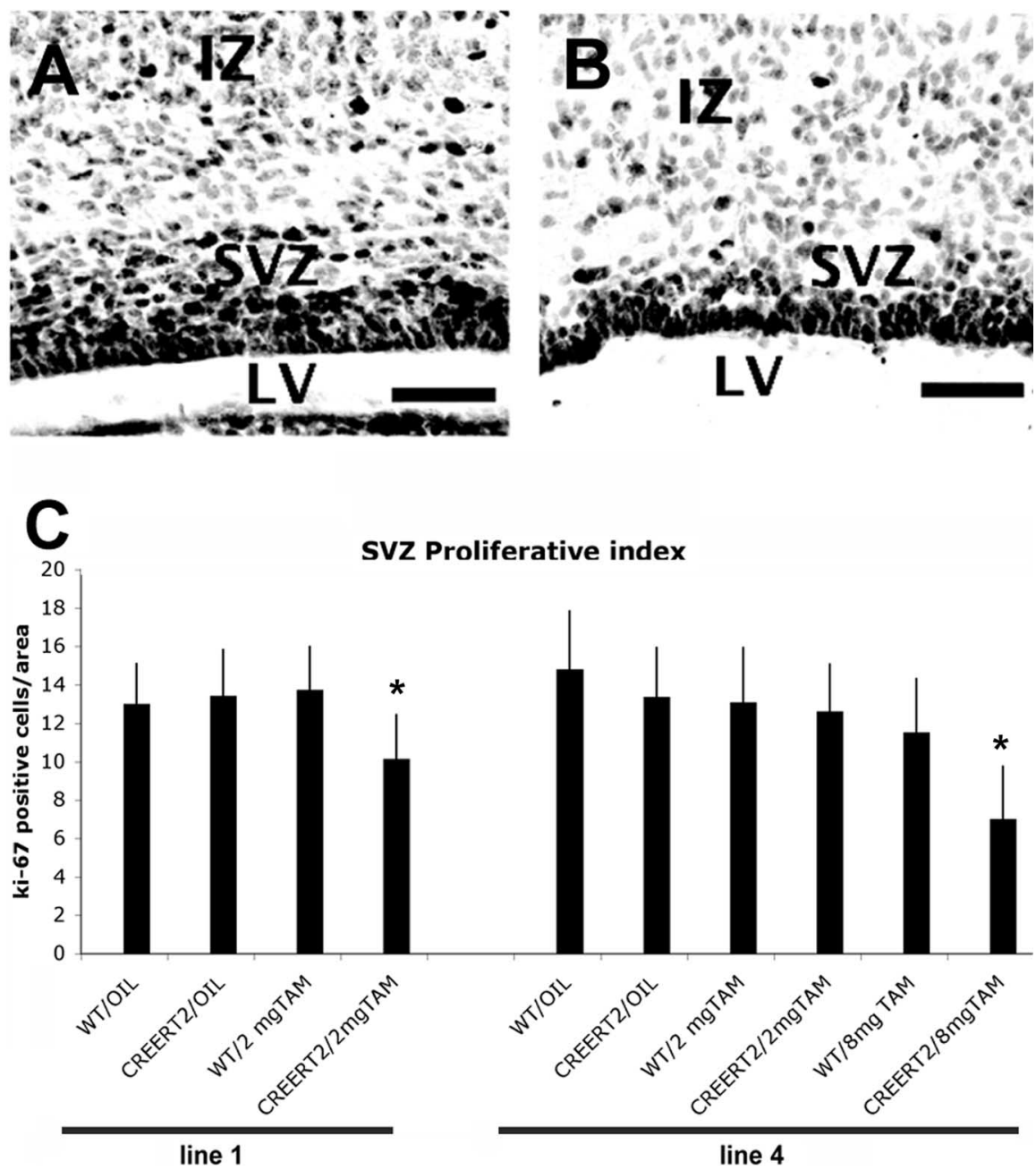

Figure 8. Ki-67 labeling (dark stain) at E19.5 on coronal sections from oil-treated $(\boldsymbol{A})$ and $2 \mathrm{mg}$ tamoxifen-treated (TAM) (B) nestin $C r e E R^{T 2}$ line 1 heterozygous embryos reveals a reduction of the number of proliferating cells in the SVZ and in the intermediate zone (IZ) of tamoxifen-treated embryos $(\boldsymbol{B})$ with respect to oil-treated control $(\boldsymbol{A})$. LV, Lateral ventricle. C, Quantification of Ki-67-positive cells in the SVZ at E19.5 in heterozygous CreER ${ }^{T 2}$ line 1 and line 4 and wild-type controls embryos after the indicated treatment performed at E10.5. Error bars represent mean $\pm S D ; n=3$ for each genotype. ${ }^{*} p<0.001$, $t$ test.
Grondona JM, Perez-Martin M, Cifuentes M, Perez J, Jimenez AJ, Perez-Figares JM, Fernandez-Llebrez P (1996) Ependymal denudation, aqueductal obliteration and hydrocephalus after a single injection of neuraminidase into the lateral ventricle of adult rats. J Neuropathol Exp Neurol 55:999-1008.

Haigh JJ, Morelli PI, Gerhardt H, Haigh K, Tsien J, Damert A, Miquerol L, Muhlner U, Klein R, Ferrara N, Wagner EF, Betsholtz C, Nagy A (2003) Cortical and retinal defects caused by dosage-dependent reductions in VEGF-A paracrine signaling. Dev Biol 262:225-241.

Hayashi S, McMahon AP (2002) Efficient recombination in diverse tissues by a tamoxifeninducible form of Cre: a tool for temporally regulated gene activation/inactivation in the mouse. Dev Biol 244:305-318.

Hicks SP, D'Amato CJ (1980) Effects of radiation on development, especially of the nervous system. Am J Forensic Med Pathol 1:309-317.

Imayoshi I, Ohtsuka T, Metzger D, Chambon P, Kageyama R (2006) Temporal regulation of Cre recombinase activity in neural stem cells. Genesis 44:233-238.

Indra $\mathrm{AK}$, Warot X, Brocard J, Bornert JM, Xiao JH, Chambon P, Metzger D (1999) Temporally-controlled site-specific mutagenesis in the basal layer of the epidermis: comparison of the recombinase activity of the tamoxifen-inducible Cre-ER(T) and CreER(T2) recombinases. Nucleic Acids Res 27:4324-4327.

Isaka F, Ishibashi M, Taki W, Hashimoto N, Nakanishi S, Kageyama R (1999) Ectopic expression of the bHLH gene Mathl disturbs neural development. Eur J Neurosci 11:2582-2588.

Jimenez AJ, Tome M, Paez P, Wagner C, Rodriguez S, Fernandez-Llebrez P, Rodriguez EM, Perez-Figares JM (2001) A programmed ependymal denudation precedes congenital hydrocephalus in the hyh mutant mouse. J Neuropathol Exp Neurol 60:1105-1119.

Kaushal D, Contos JJ, Treuner K, Yang AH, Kingsbury MA, Rehen SK, McConnell MJ, Okabe M, Barlow C, Chun J (2003) Alteration of gene expression by chromosome loss in the postnatal mouse brain. J Neurosci 23:5599-5606.

tein ATRX is critical for neuronal survival during corticogenesis. J Clin Invest 115:258-267.

Betz UA, Vosshenrich CA, Rajewsky K, Muller W (1996) Bypass of lethality with mosaic mice generated by Cre-loxP-mediated recombination. Curr Biol 6:1307-1316.

Crews L, Wyss-Coray T, Masliah E (2004) Insights into the pathogenesis of hydrocephalus from transgenic and experimental animal models. Brain Pathol 14:312-316.

Davy BE, Robinson ML (2003) Congenital hydrocephalus in hy3 mice is caused by a frameshift mutation in Hydin, a large novel gene. Hum Mol Genet 12:1163-1170.

Dobkin BH (1978) Syncope in the adult Chiari anomaly. Neurology 28:718-720.

Dominguez-Pinos MD, Paez P, Jimenez AJ, Weil B, Arraez MA, Perez-Figares JM, Rodriguez EM (2005) Ependymal denudation and alterations of the subventricular zone occur in human fetuses with a moderate communicating hydrocephalus. J Neuropathol Exp Neurol 64:595-604.

Feil R, Brocard J, Mascrez B, LeMeur M, Metzger D, Chambon P (1996) Ligand-activated site-specific recombination in mice. Proc Natl Acad Sci USA 93:10887-10890.

Fransen E, D'Hooge R, Van Camp G, Verhoye M, Sijbers J, Reyniers E, Soriano P, Kamiguchi H, Willemsen R, Koekkoek SK, De Zeeuw CI, De Deyn PP, Van der Linden A, Lemmon V, Kooy RF, Willems PJ (1998) L1 knockout mice show dilated ventricles, vermis hypoplasia and impaired exploration patterns. Hum Mol Genet 7:999-1009.
Kim GJ, Park SY, Kim H, Chun YH, Park SH (2001) Chromosomal aberrations in neuroblastoma cell lines identified by cross species color banding and chromosome painting. Cancer Genet Cytogenet 129:10-16.

Klezovitch O, Fernandez TE, Tapscott SJ, Vasioukhin V (2004) Loss of cell polarity causes severe brain dysplasia in Lgll knockout mice. Genes Dev 18:559-571.

Kos CH (2004) Cre/loxP system for generating tissue-specific knockout mouse models. Nutr Rev 62:243-246.

Lin T, Sandusky SB, Xue H, Fishbein KW, Spencer RG, Rao MS, Francomano CA (2003) A central nervous system specific mouse model for thanatophoric dysplasia type II. Hum Mol Genet 12:2863-2871.

Liu W, Sun X, Braut A, Mishina Y, Behringer RR, Mina M, Martin JF (2005) Distinct functions for Bmp signaling in lip and palate fusion in mice. Development 132:1453-1461.

Loonstra A, Vooijs M, Beverloo HB, Allak BA, van Drunen E, Kanaar R, Berns A, Jonkers J (2001) Growth inhibition and DNA damage induced by Cre recombinase in mammalian cells. Proc Natl Acad Sci USA 98:9209-9214.

Mignone JL, Kukekov V, Chiang AS, Steindler D, Enikolopov G (2004) Neural stem and progenitor cells in nestin-GFP transgenic mice. J Comp Neurol 469:311-324.

Pfeifer A, Brandon EP, Kootstra N, Gage FH, Verma IM (2001) Delivery of the Cre recombinase by a self-deleting lentiviral vector: efficient gene targeting in vivo. Proc Natl Acad Sci USA 98:11450-11455. 
Pirvola U, Ylikoski J, Trokovic R, Hebert JM, McConnell SK, Partanen J (2002) FGFR1 is required for the development of the auditory sensory epithelium. Neuron 35:671-680.

Raab S, Beck H, Gaumann A, Yuce A, Gerber HP, Plate K, Hammes HP, Ferrara N, Breier G (2004) Impaired brain angiogenesis and neuronal apoptosis induced by conditional homozygous inactivation of vascular endothelial growth factor. Thromb Haemost 91:595-605.

Ramanathan R, Wilkemeyer MF, Mittal B, Perides G, Charness ME (1996) Alcohol inhibits cell-cell adhesion mediated by human L1. J Cell Biol 133:381-390.

Rehen SK, McConnell MJ, Kaushal D, Kingsbury MA, Yang AH, Chun J (2001) Chromosomal variation in neurons of the developing and adult mammalian nervous system. Proc Natl Acad Sci USA 98:13361-13366.

Sakata-Haga H, Sawada K, Ohnishi T, Fukui Y (2004) Hydrocephalus following prenatal exposure to ethanol. Acta Neuropathol (Berl) 108:393-398.

Schmidt EE, Taylor DS, Prigge JR, Barnett S, Capecchi MR (2000) Illegitimate Cre-dependent chromosome rearrangements in transgenic mouse spermatids. Proc Natl Acad Sci USA 97:13702-13707.

Silver DP, Livingston DM (2001) Self-excising retroviral vectors encoding the Cre recombinase overcome Cre-mediated cellular toxicity. Mol Cell $8: 233-243$.

Soriano P (1999) Generalized lacZ expression with the ROSA26 Cre reporter strain. Nat Genet 21:70-71.

Thuret S, Alavian KN, Gassmann M, Lloyd CK, Smits SM, Smidt MP, Klein R, Dyck RH, Simon HH (2004) The neuregulin receptor, ErbB4, is not required for normal development and adult maintenance of the substantia nigra pars compacta. J Neurochem 91:1302-1311.

Thyagarajan B, Guimaraes MJ, Groth AC, Calos MP (2000) Mammalian genomes contain active recombinase recognition sites. Gene 244:47-54.
Tomita S, Ueno M, Sakamoto M, Kitahama Y, Ueki M, Maekawa N, Sakamoto H, Gassmann M, Kageyama R, Ueda N, Gonzalez FJ, Takahama Y (2003) Defective brain development in mice lacking the Hif-1alpha gene in neural cells. Mol Cell Biol 23:6739-6749.

Treutelaar MK, Skidmore JM, Dias-Leme CL, Hara M, Zhang L, Simeone D, Martin DM, Burant CF (2003) Nestin-lineage cells contribute to the microvasculature but not endocrine cells of the islet. Diabetes 52:2503-2512.

Tronche F, Kellendonk C, Kretz O, Gass P, Anlag K, Orban PC, Bock R, Klein $\mathrm{R}$, Schutz G (1999) Disruption of the glucocorticoid receptor gene in the nervous system results in reduced anxiety. Nat Genet 23:99-103.

Trumpp A, Depew MJ, Rubenstein JL, Bishop JM, Martin GR (1999) Cremediated gene inactivation demonstrates that FGF8 is required for cell survival and patterning of the first branchial arch. Genes Dev 13:3136-3148

Uno S, Wang B, Shertzer HG, Nebert DW, Dalton TP (2003) Balancer-Cre transgenic mouse germ cells direct the incomplete resolution of a triloxP-targeted Cyplal allele, producing a conditional knockout allele. Biochem Biophys Res Commun 312:494-499.

Wagner C, Batiz LF, Rodriguez S, Jimenez AJ, Paez P, Tome M, Perez-Figares JM, Rodriguez EM (2003) Cellular mechanisms involved in the stenosis and obliteration of the cerebral aqueduct of hyh mutant mice developing congenital hydrocephalus. J Neuropathol Exp Neurol 62:1019-1040.

Xie Y, Skinner E, Landry C, Handley V, Schonmann V, Jacobs E, Fisher R, Campagnoni A (2002) Influence of the embryonic preplate on the organization of the cerebral cortex: a targeted ablation model. J Neurosci 22:8981-8991.

Yang AH, Kaushal D, Rehen SK, Kriedt K, Kingsbury MA, McConnell MJ, Chun J (2003) Chromosome segregation defects contribute to aneuploidy in normal neural progenitor cells. J Neurosci 23:10454-10462. 